\title{
REPLICATION OF A PSYCHOSOCIAL REHABILITATION PROGRAM: A CASE STUDY ANALYSIS OF SUPPORTED EDUCATION
}

\section{Carol T. Mowbray, Lorraine M. Gutierrez, Chyrell D. Bellamy,} Steve Szilvagyi, and Shari Strauss

University of Michigan

This article describes a strategy of organizing community stakeholder groups for the purpose of planning and implementing an innovative mental health program—supported education services for adults with mental illnesses who were interested in pursuing postsecondary education. A common planning framework was used in several different communities within the same state. The framework is described, as well as each community's characteristics and their planning and development activities-those typically identified in the literature as predictors of successful innovation diffusion efforts. We then present the outcomes of the planning process in each community and suggest conclusions about which community characteristics and/or planning activities seem to be most associated with success. (C) 2003 Wiley Periodicals, Inc.

Among the most difficult and long-standing social problems in many communities is the stigma associated with major mental illness, resulting in exclusion of individuals with psychiatric disabilities from normalized activities and community resistance to integrating these citizens into housing, employment, education, and other aspects of community life. Government and foundation funding initiatives have increasingly

This article was funded by grant \#KD1-SM52684 from the Center for Mental Health Services, SAMHSA, to the School of Social Work, University of Michigan.

Correspondence to: Carol T. Mowbray, Supported Education Community Action Group, School of Social Work, The University of Michigan, 1080 South University, Ann Arbor, MI 48109-1106. E-mail: secag@umich.edu 
supported community coalitions or collaboratives as social change methods to address such complex and challenging social problems (Mizrahi \& Rosenthal, 2001). This article describes the results of efforts to initiate an innovative psychiatric rehabilitation service in the community for individuals with serious mental illness, with a community collaborative, through dissemination activities that utilized community organizing, participatory action research, and empowerment evaluation.

\section{RESEARCH ON KNOWLEDGE DIFFUSION AND COMMUNITY ORGANIZING}

The use of community collaboratives and coalitions for the implementation and dissemination of innovations in service delivery is founded, in part, on knowledge of effective technology transfer methods. The research on community organizing and on the diffusion of innovations (Minkler, 1997; Rogers, 1995) has helped to develop change methods and to analyze these efforts and their effects. Rogers (1995) identified specific steps and conditions to optimize the diffusion of innovations. His work indicates that the acceptance of an innovation involves a process of change with five components:

1. knowledge-being exposed to the existence of the innovation and how it functions

2. persuasion-forming a favorable attitude towards the innovation

3. decision-engaging in activities that lead to a choice to adopt or reject the innovation

4. implementation-putting the innovation into use

5. confirmation-seeking reinforcement for an innovation already adopted.

These steps and their outcomes are influenced by the following key characteristics of the principal parties and the context: (a) the attributes of the innovationsignificant characteristics of the innovation that influence its adoption include its perceived relative advantage, compatibility with existing values, perceived difficulty or complexity, observability, and incentives associated with its use. (b) The adopter of the innovation (the individual considering adopting a new practice)—characteristics that influence an individual decision to change, including higher socio-economic status, higher education, more contact with change agents, and more social participation. (c) Characteristics of diffusion networks-homophilous networks (made up of similar entities) promote horizontal diffusion (new ideas spreading horizontally, not vertically) and therefore slow down diffusion, especially when compared to heterophilous networks. (d) The attributes of the principal change agent (the individual promoting the change)-influential characteristics include better coping abilities, greater rationality, and intelligence.

Rogers' steps and the characteristics he associates with change are focused on the individual level. Research applying this knowledge to organizations has found that the organization's openness to change is also a critical element in the process. To implement change successfully, the organization must find ways to fit the innovation to its overall mission or modify the innovation to conform to organizational structures. When transfer is successful, the innovation becomes integrated into the workings of the organization (Davis, 1978; Herie \& Martin, 2002). 


\section{DIMENSIONS OF COMMUNITY ENVIRONMENTS INVOLVED IN CHANGE}

Work in technology transfer and diffusion of innovations has occurred primarily in agriculture, the military, and education (Herie \& Martin, 2002). To make this framework relevant to social problems at the community level, adaptations are necessary. The literature from community practice and processes is relevant to the adoption of innovations and to modifications of the technology transfer knowledge base necessary to address social problems. Maton (2000), conceptualizing ways to address complex social environments, identified four relevant dimensions of community and the activities necessary to produce change in each:

1. The instrumental environment encompasses those activities undertaken to accomplish core goals. It is addressed through capacity building to improve organizational effectiveness.

2. The structural environment includes the distribution of resources and power across existing groups and the opportunity structures to allow access to these resources. Changing the structural environment is addressed through group empowerment.

3. The relational environment concerns the quality and nature of intergroup and personal relationships in a community. Intervention activities must focus on relationship building toward norms of a caring community and an inclusive society, interconnecting diverse elements with strong "social glue."

4. The cultural environment encompasses belief systems, values, and practices. "Otherdenigration" and "self-absorption" are two facets of current culture that can impede solution of social problems and must be addressed through activities that challenge cultural barriers.

Although differently organized and situated at the community rather than the individual level, these dimensions, overall, seem to encompass the characteristics relevant for technology transfer, put forward by Rogers (1995). That is, the attributes of the innovation and its compatibility with the adopter's values are congruent with Maton's description of the cultural environment. Similarly, Maton's description of the structural environment corresponds to Rogers' notion of the importance of the social and status characteristics of the adopter. Rogers' identification of the importance of homophilous versus heterophilous networks relates to Maton's relational environment. Finally, Maton's instrumental environment, at the individual level described by Rogers, would be reflected in the importance of the education and intelligence of the adopter and the change agent. These relationships are portrayed in Table 1.

Maton's dimensions are also quite similar to the mechanisms of collaboration identified by Wondolleck and Yaffee (2000) for natural resource management: building understanding through exchange of information and ideas (\#3); providing a mechanism for effective decision making (\#2); coordinating crossboundary activities (\#4); and developing agency capacity (\#1). In the project described below, Maton's dimensions for community change efforts were used to frame a process of adopting a new innovation in psychiatric rehabilitation-supported education (for a graphic representation, also see Table 1). 
Table 1. Framework for Conceptualizing SE-CAG Stages and Indicators

\begin{tabular}{|c|c|c|c|}
\hline $\begin{array}{c}\text { Dimensions of } \\
\text { Community Relevant } \\
\text { to Change } \\
\text { (Maton, 2000) }\end{array}$ & $\begin{array}{l}\text { Key Characteristics } \\
\text { Relevant to Change } \\
\quad \text { (Rogers, 1995) }\end{array}$ & SE-CAG Stages & $\begin{array}{c}\text { SE-CAG Indicators } \\
\text { (predictors) }\end{array}$ \\
\hline $\begin{array}{l}\text { Structural environment- } \\
\text { distribution of resources } \\
\text { and power }\end{array}$ & $\begin{array}{l}\text { Social and status } \\
\text { characteristics of } \\
\text { adopter }\end{array}$ & $\begin{array}{l}\text { Stage I-Involvement } \\
\text { of key stakeholders } \\
\text { in planning } \\
\text { Stage II-Resource } \\
\text { assessment }\end{array}$ & $\begin{array}{l}\text { Letters of intent } \\
\text { Involvement of } \\
\text { organizational } \\
\text { leadership } \\
\text { Who is in charge of } \\
\text { project? } \\
\text { Relevant local } \\
\text { circumstances }\end{array}$ \\
\hline $\begin{array}{l}\text { Instrumental environment- } \\
\text { activities necessary to } \\
\text { accomplish goals }\end{array}$ & $\begin{array}{l}\text { Education and } \\
\text { intelligence of adopter } \\
\text { and change agent }\end{array}$ & $\begin{array}{l}\text { Stages II and IV- } \\
\text { Information on SEd } \\
\text { and TA } \\
\text { Stage III-Needs } \\
\text { assessment }\end{array}$ & $\begin{array}{l}\text { Number of stakeholders } \\
\text { attending orientation } \\
\text { and TA } \\
\text { Funding and TA } \\
\text { received from SE-CAG }\end{array}$ \\
\hline $\begin{array}{l}\text { Relational environment- } \\
\text { quality of intergroup and } \\
\text { interpersonal relationships }\end{array}$ & $\begin{array}{l}\text { Homophilous versus } \\
\text { heterophilous networks }\end{array}$ & $\begin{array}{l}\text { Stage I-Stakeholder } \\
\text { involvement in } \\
\text { planning }\end{array}$ & $\begin{array}{l}\text { Extent of involvement } \\
\text { of relevant stakeholders }\end{array}$ \\
\hline $\begin{array}{l}\text { Cultural environment- } \\
\text { beliefs, values and } \\
\text { practices }\end{array}$ & $\begin{array}{l}\text { Attributes of } \\
\text { innovation, } \\
\text { compatibility with } \\
\text { values }\end{array}$ & $\begin{array}{l}\text { Stage III-Needs } \\
\text { assessment }\end{array}$ & $\begin{array}{l}\text { Consumer involvement } \\
\text { in process } \\
\text { Needs assessment } \\
\text { results } \\
\text { Educational levels of } \\
\text { clients and community }\end{array}$ \\
\hline
\end{tabular}

\section{BACKGROUND: THE PROJECT}

Supported education (SEd), similar to supported employment and supported housing, takes a rehabilitation approach in providing assistance, preparation, and support to adults with psychiatric disabilities who wish to pursue postsecondary education or training. Typical SEd programs provide the following services: individual counseling and assessment, tutoring, advocacy, practical individualized assistance, help in developing an educational plan, trouble-shooting, linking to resources, accessing financial aid, academic skills training, and time management. Supported education follows five established principles to foster social integration: presence in a regular community (an educational site); participation in socially valued activities (higher education); skill enhancement (acquisition and practice of social and academic skills); image enhancement (role transformation from the socially devalued role of "patient" to that of "student"); and autonomy (choosing the classes/training needed for the desired vocational path).

Following completion of a successful research demonstration project on supported education (funded through the federal Center for Mental Health Services), we applied for and received funding for a grant to help disseminate and support the replication of SEd in three communities in Michigan. The project was called the Supported Education Community Action Grant (SE-CAG). 


\section{THE SE-CAG PROCESS}

SE-CAG's process methods included elements of empowerment evaluation, participatory action research, social action, and community organizing. Common to these approaches, are principles of building on strengths within communities, maximizing choice, and increasing involvement and participation (Fetterman, 2002; Gutierrez, GlenMaye, \& DeLois, 1995)—the expected result being community stakeholders working with each other to help themselves. According to Fetterman, Kaftarian, and Wandersman (1996), "training, facilitation, advocacy, illumination and liberation" are just some of the ways to accomplish this goal (p. 9).

SE-CAG utilized an 18-month planning process which addressed each of the environmental dimensions described by Maton (2000), to maximize the likelihood of change (see also Mowbray, Bellamy, Megivern, \& Szilvagyi, 2001). Stage I involved organizing and engaging key stakeholders. Stage II focused on education about SEd and identification of relevant community resources. In Stage III, sites completed assessments of educational needs and barriers to their attainment; and in Stage IV, sites were offered technical assistance to overcome the barriers and were encouraged to formulate their own, locally responsive, supported education plans. Detailed activities associated with each stage are described below, followed by an analysis of how the stages relate to Maton's dimensions of community environments.

The focus of Stage I was on the planning process, and on securing the involvement of these five stakeholder groups: consumers, family members, higher education institutions, vocational rehabilitation agencies, and mental health services. Lack of involvement of these key stakeholders can create significant barriers to SEd implementation (Moxley, Mowbray, \& Brown, 1993). To begin the process, an advisory group to the project was established at the state level; the group developed and sent out Requests for Proposals, to stimulate interest in supported education by initiating a competitive process. This was also in recognition of the fact that the readiness of a community to solve its problems is critical to change efforts (Wolff, 2001). SE-CAG staff utilized promotional techniques such as mailings to all stakeholders at potential local sites; press releases and announcements in relevant newsletters to educate constituents and further engage their interests; and a SE-CAG brochure to publicize SEd.

Seven community-based, mental health agencies from six different communities submitted applications to receive assistance in developing a SEd program. The criteria for site selection were demonstration of SEd principles, involvement of stakeholder groups, having a strong agency commitment, and addressing multicultural issues. Based on Advisory Council rankings of the applications, five sites were chosen; two were rejected because applicants had not demonstrated any coordination with other stakeholders.

In Stage II, SE-CAG offered all-day workshops, on-site, to educate local stakeholders about SEd and about the ways it has been implemented within differing resource environments. A recognized national expert detailed the goals and operation of supported education. The most persuasive communications were testimonials from graduates of Detroit's Supported Education Program (MSEP). Assessing community resources for SEd was also covered; for example, who to engage in the process; how and what information to collect; and how to organize materials. SE-CAG encouraged sites to identify and engage local consumers pursuing higher education in order to cultivate leadership. 
The planning groups at each site were asked to produce resource assessments, integrating information compiled by all the stakeholders in their group. For the most part, planning group members were surprised at the availability of relevant resources in their communities. Based on reviews of resource assessments by the state level, project advisory group (especially, the extent to which meaningful stakeholder involvement was evident), three agencies were selected to receive more intensive support and TA from SE-CAG. This consisted of monetary and SE-CAG staff support to conduct needs assessments, training sessions providing information for replication, hands-on TA, and on-site consultation. The other three sites were free to participate in group TA and training sessions, but did not receive funding or on-site assistance.

For Stage III of SE-CAG, the planning groups from the three chosen sites worked closely with project staff on needs assessments and on identification and resolution of barriers. A second workshop, combining representatives from all the sites, focused on needs assessment. Training was provided and a handbook was distributed, describing methods for collecting information from consumers, providers, and referral sources, building on the resource assessments previously conducted, and outlining advantages and disadvantages of each method. The benefits of meaningful consumer involvement throughout the needs assessment process were emphasized. Each site was given funding to offset the local costs of conducting the needs assessment, and was assigned a field consultant to provide technical assistance by phone or in person. Needs assessments were completed about 3 months later. Needs assessment results were used to adapt models of SEd to meet local needs and to identify barriers. Surprisingly, barriers identified included the attitudes of potential participants (fear, reluctance, ambivalence) and of mental health agency staff (e.g., consumers are not capable; education is too stressful, etc.).

In Stage IV, SE-CAG staff and consultants provided information or technical assistance to help each site access available resources and overcome the identified barriers. Each host agency, along with local stakeholders, developed an implementation plan after deciding on strategies for addressing the barriers. The resource and needs assessments served as major tools for producing the SEd implementation plans. These plans were reviewed by SE-CAG staff for their completeness, responsiveness to participant needs, adaptation to local conditions, feasibility in light of identified barriers, and inclusiveness. Feedback to each site focused on resolution of identified weaknesses and on recommended improvements to ensure successful SEd implementation.

The relationships between Maton's dimensions of community environments and the SE-CAG stages are presented in Table 1. SE-CAG Stages II and IV most clearly addressed the instrumental environment, by providing information on how supported education programs had been implemented in other locations, with varying amounts and kinds of resources, and by providing technical assistance as to how the local site might overcome local barriers. The Needs Assessments of Stage III could also be seen as relevant to the instrumental environment, in that local needs and desires of consumers were identified. However, the Needs Assessment activity also addressed the cultural environment, in that it provided the planners with new images of consumers. That is, in conducting interviews, distributing surveys, and running focus groups for the needs assessments, consumers were now seen as much more capable. Consumers providing information about their prior educational experiences, hopes, and aspirations also changed the culture by placing these individuals in a more strengthsoriented and sympathetic light and by giving them an instrumental role as part of a problem-solving team. 
In the SE-CAG process, the structural environment was the focus of the Resource Assessments of Stage II. All participants, including consumers and advocates, came together to become aware of many supportive resources not previously known. Knowledge is power, according to one old dictum. Having knowledge of relevant community resources can thus be the first step to increased resource acquisition and opening up opportunity structures. Finally, the relational environment was addressed in Stage I and throughout the rest of the SE-CAG process, in that the planning group brought together significant, but typically noninteracting or disagreeing stakeholders. The planning group members came together for a pleasant task (program development) in a positive climate (the project supplied funds to purchase food and an adequate meeting space), to complete very concrete products, which relied on the diverse knowledge and connections of each stakeholder. In short, the process was designed to build relationships among the stakeholder groups and thus to enhance commitment to achieving the shared goal of developing and implementing a local supported education program.

\section{THE STATE CONTEXT}

Antithetical to the intent and process of the Supported Education Community Action Grant were state level emphases on cutting costs and implementing managed care. In previous decades, Michigan was a leader in decreased utilization of state psychiatric facilities and increased availability of community-based care. Particularly noteworthy was the emphasis on psychiatric rehabilitation, having operational nearly 50 clubhouses (a psychiatric rehabilitation program designed to help consumers prepare for and obtain employment), over 100 assertive community treatment teams and, at one time, 35 Fairweather Lodge programs (a psychosocial rehabilitation group residential and employment program). In the 1990s, the State's Mental Health Code was revised to require consumer participation on local $\mathrm{CMH}$ boards and to mandate personcentered planning for mental health services. However, in the mid-1990s, the State began to change Medicaid reimbursement systems to institute a managed care system and get control of escalating health-care costs. These changes produced increased demands, but less money to meet them. One method of cutback was to remove experienced (and expensive) clinical staff from front-line positions and replace them with less experienced and lower paid direct care workers. In many cases, the result was chaos-higher staff turnover, and less appropriate and lower quality servicescertainly not ideal conditions for planning and instituting program change.

\section{OVERVIEW}

In the next sections of this article, we present information on the local activities carried out at each site during the SE-CAG process as well as the outcomes. The site activities selected for documentation are those identified in the literature as most predictive of community organizing success: involvement and participation of leaders, consumers, and relevant others; amount of activity; completion of expected products and their quality; resources accessed; and congruence of the educational goals for the majority of service recipients with the SEd intent of providing support for postsecondary education (Kegler, Twiss, \& Look; 2000). We hypothesized that differences in these variables across sites would serve as predictors for the overall success of the planning process-the system-level changes that came about as well as changes in 
programming that occurred during SE-CAG. However, we also acknowledged that the state-level context and local circumstances were likely to play a role. In the discussion, we analyze the results in terms of whether the SE-CAG planning process was successful and what factors seemed most relevant for local sites' outcomes. We then comment on these case study results vis-à-vis the processes and factors suggested as significant determinants of community change and of adoption of innovations, based on the literature.

\section{METHODS}

\section{Settings}

The initial call for proposals from SE-CAG resulted in seven letters of intent submitted from six different communities. A brief overview of these communities is presented below.

Transition City $(\mathrm{MSA}=162,300$; population = 11,182; density 2,545.7/sq.mi.) -A small urban area at the edge of a largely rural county, Transition City has been going through economic upheavals for quite some time with the waxing and waning of various manufacturing industries. Unemployment is high and business development is low. In summer, the city is a major crossroad for migrant farm workers. The area's approach to delivery of mental health services relies heavily on traditional, medical model approaches, although its relatively small size and lack of social service resources give staff some latitude to experiment with newer psychiatric rehabilitation approaches. Transition City's population is $92.4 \%$ Black, $5.5 \%$ White, and $0.6 \%$ Latino, with a median household income of $\$ 17,471$ (2000 census; U.S. Census Bureau, 2000).

Blue Collar Town (MSA $=213,800$; population $=61,699$; density 3,542.9/sq. mi.) had its wealth at the turn of the 20th century, based on the lumber industry that flourished in Michigan. As this industry waned, the city sought new economic activity as a manufacturing center and parts supplier to the growing auto industry. It also became a place where many migrant farm workers settled, due to its proximity to a large farming region. Mental health services in this area had long been a poor relation in the quest for local funding, but a succession of relatively strong and effective CMH directors had begun to build new approaches among the heavily entrenched population of Adult Foster Care (AFC) home providers. The demographics of the city are $43.3 \%$ Black, $47 \%$ White, and $11.7 \%$ Latino, with a median household income of $\$ 26,485$ (2000 census).

Executive Village $(\mathrm{MSA}=1,218,900$; population $=66,337$; density 3,318.2/sq. mi. $)$ Another auto town, Executive Village, is in one of the wealthiest counties in the United States. Formerly the home to a large and antiquated state mental hospital, it now houses a high proportion of people with mental illness. It is surrounded by growing suburbs populated by relatively wealthy automotive executives who fled urban blight, and have a very reactionary approach to the delivery of mental health services. Although resources are prevalent, attitudes have prevented the development of locally controlled and progressive community programs. Consequently, mental health services in this community are characterized by a heavily hierarchic (and expensive) administrative structure overseeing traditional, medical-model outpatient, partial hospitalization, and AFC programs. The population of Executive Village is $10.1 \%$ Black, $82.8 \%$ White, and $2.4 \%$ Latino, with a median household income of $\$ 61,907$ (2000 census). 
Factory Town $(\mathrm{MSA}=437,700$ 2000; population $=124,943$; density 3,714.9/sq. mi.) - In this quintessential rust-belt town, a large portion of the population is employed (or in hard times, unemployed) by the auto industry. The town is suffused with a work ethic, so its clubhouse program has a healthy focus on transitional employment. The $\mathrm{CMH}$ agency has had a number of working contacts with local community colleges for clients who want to return to school. The town's population is $53.3 \%$ Black, $41.4 \%$ White, and 3\% Latino, with a median household income of $\$ 28,015$ (2000 census).

Medtown $(\mathrm{MSA}=233,800$; population $=77,145$; density $424.6 /$ sq.mi. $)$ has a diversified workforce, with several mid to large industries-one of the largest being pharmaceuticals. The city has a large state university, a prestigious college, and a well-developed community college. It is also home to a large state mental hospital, and many former patients have settled in the area. Given the presence of the pharmaceutical company and the state hospital, it is not surprising that mental health services here are medically oriented. However, a clubhouse program had been working with some members who wished to return to college. The Medtown population is $20.6 \%$ Black, $70.8 \%$ White, and $4.3 \%$ Latino, with a median household income of $\$ 31,189$ (2000 census).

University Village $(\mathrm{MSA}=445,600 ;$ population $=119,128$; density 3,399/sq.mi.). In addition to significant auto industry employment, University Village houses the state's largest university, and many state government workers-contributing to a higher than average income level. Its community mental health services have a history of being innovative, boasting the state's second-oldest psychiatric rehabilitation clubhouse. Mental health advocacy groups are quite active and provide ongoing input to the local mental health administration. The demographics of University Village are $21.9 \%$ Black, $65.3 \%$ White, and $10 \%$ Latino, with a median household income of $\$ 34,833$ (2000 census).

\section{MEASURES}

Information for the current analysis was obtained from several sources: project records, material submitted by the sites, process recordings during SE-CAG meetings and technical assistance (TA) sessions, and phone interviews which occurred about 6 months following project completion. Information obtained from each of these sources is described below.

Project Records. Documentation included ratings from SE-CAG staff and Advisory Council members of material produced at each site (such as, initial letters of intent and other required products), attendance of each site's planning group members at SE-CAG meetings and TA sessions, amount of funding and staff TA provided to each site, evaluation of each site's supported education plan, and their progress in setting up ongoing SEd services.

Material Submitted by the Sites. Initial letters of intent, resource assessments, needs assessments, plus information on activities at each site, such as number of planning meetings held, stakeholders represented, and methods used in the needs assessments.

Follow-up Phone Interviews. The phone interviews were all conducted by the last author, after having worked with the project for more than a year and receiving training and consultation with the project directors on the interview intent and process. Those 
individuals contacted for interviews were chosen based on their involvement in their local site's supported education planning and their participation in SE-CAG training events; thus, at each site the stakeholders varied. Interviewees included SEd program coordinators, clubhouse directors, vocational rehabilitation staff, and CMH staff. Interviews ranged in length from 30 to 90 minutes, based on the respondent's level of involvement in the program, the number of stories shared, and the level of development of the supported education initiative. The interview covered the planning and community organizing process, and the implementation and operation of the SEd program. For this report, we included answers to the following questions from the phone interview: extent to which consumers were involved in planning, involvement of other stakeholder groups, which stakeholders had the most impact, organizational changes that occurred (outside of SE-CAG activities), information on supported education services currently being provided (number of people served in the past 12 months and their educational involvement), interagency linkages established locally, intraagency linkages, whether relationships were established with other supported education programs, changes in the agency as a result of SE-CAG involvement, other accomplishments due to SE-CAG involvement, and what the respondent would do differently in retrospect.

\section{RESULTS}

Table 2 provides descriptions and ratings of activities at each site associated with the SE-CAG planning process and other predictors of outcomes. These variables are grouped according to domain: structural, instrumental, relational, or cultural. The data from each site are presented as hypothesized predictors of outcomes resulting from the planning process. The outcomes, i.e., what programmatic and/or system-level changes occurred in each of the three participating (recipients of technical assistance) sites, are listed in Table 3. The "success" of the grant, according to federal officials, was based on the extent to which, at each site, the project had a sponsor and staff, a higher education collaborator, whether the planning group had regular meetings, whether the resource and needs assessments were done, whether there was an SEd plan, and the extent to which consumers, family members, and funding agencies were involved. The activities and results by site are described below for all six communities.

\section{Medtown}

This site was scored \#1 on the initial letter of intent, mainly because supported education activities were already underway at this clubhouse, so the administration and the CMH Board were supportive. There was a good working relationship between the clubhouse and vocational rehabilitation staff and discussions had begun with the local community college. At the beginning of the SE-CAG project, this site showed the expected levels of participation in training events and other meetings. Assigned staff from the lead agency conducted local meetings with fairly good attendance and produced a complete needs assessment, although it was weighted towards the opinions of clinicians rather than consumers or advocates. Although consumers and family members attended meetings, they were not key figures in the planning process.

However, there were areas of concern in Medtown's predictor profile: first, the individual in charge of the project was at a contractual agency-three levels down 
from the top administration at the local CMH funding source; second, the membership of the clubhouse leading the effort was predominantly at the Adult Basic Education level; few were appropriate, at that time, to pursue postsecondary education or training; and third, local circumstances were not favorable in that funding became tight and there was overall agency turmoil due to the shift to managed care. The effect of the latter was probably exacerbated by the fact that the supported education program had not garnered a lot of local support (not from clubhouse members because few of them needed this service, and not from other consumers or family members because they had limited involvement). One might also speculate that the preexistence of a supported education service may have been a negative at this site; that is, it may have made upper management less interested in or enthusiastic about a new initiative, and it may have made the clubhouse staff more complacent about accessing and utilizing help from SE-CAG. (In support of this speculation, we note the lower number of TA visits requested by this site.)

Nevertheless, Medtown's involvement in SE-CAG did have some identifiable benefits. In the short run, SE-CAG funding was able to "save" the position of SEd coordinator from funding cuts; without this support she would have been reassigned to a totally different function. Thus, the supported education program continued, rather than being abandoned. Second, there was some, albeit minor, expansion in the program, in that office space was obtained at the community college and there were a few more people from the clubhouse pursuing higher education and following through with college classes. Through an individual counseling approach to SEd, in the 2 years following the planning activities, eight individuals were served in Medtown; seven made it through their community college classes and four reenrolled. Interestingly, the major impact of this site's involvement in SE-CAG was long term. That is, from doing the needs assessment and including programs and key informants outside their clubhouse, the SEd program identified a group of young adults, with serious mental illness, who needed community-based services, but were not attending any programs. These young adults perceived consumers at the clubhouse as too different from themselves (older, more impaired, not interested in going to college), and so did not come to the club. As a result of the SE-CAG Needs Assessment data, the clubhouse was able to put together and gain support for a plan to initiate a new program-a separate, downtown clubhouse for young adults, in which supported education services would be a key component. Plans have been developed and approved and this new program should be open shortly.

\section{Factory Town}

The initial letter of intent from this site was ranked in the middle. However, the startup of the SE-CAG project was auspicious. A large number of individuals attended the first orientation meeting, representing numerous and diverse stakeholder groups: disability advocates, several postsecondary institutions, and the local Alliance for the Mentally Ill (family/advocacy) group; consumer participation was weaker. Factory Town had active participation in SE-CAG activities up through the Needs Assessment (NA); that is, staff attended SE-CAG sessions and turned in a good NA report, predominantly surveying consumers. However, there were problematic signs in Factory Town even early on: most notable was the fact that the individual in charge was three levels down in the CMH hierarchy. Local circumstances had a significant impact during the planning phase; a new executive director was hired, and managed care was being 


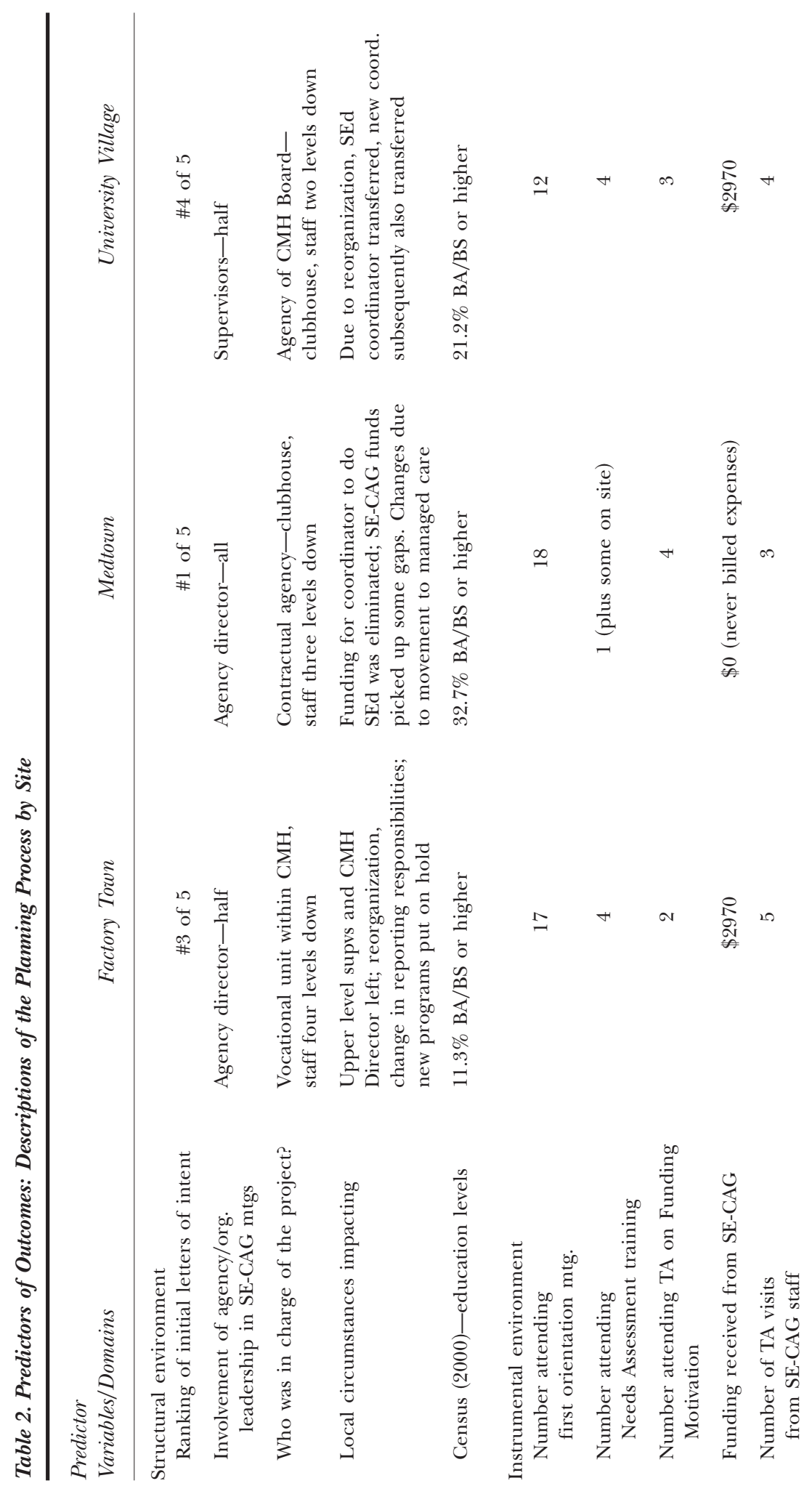



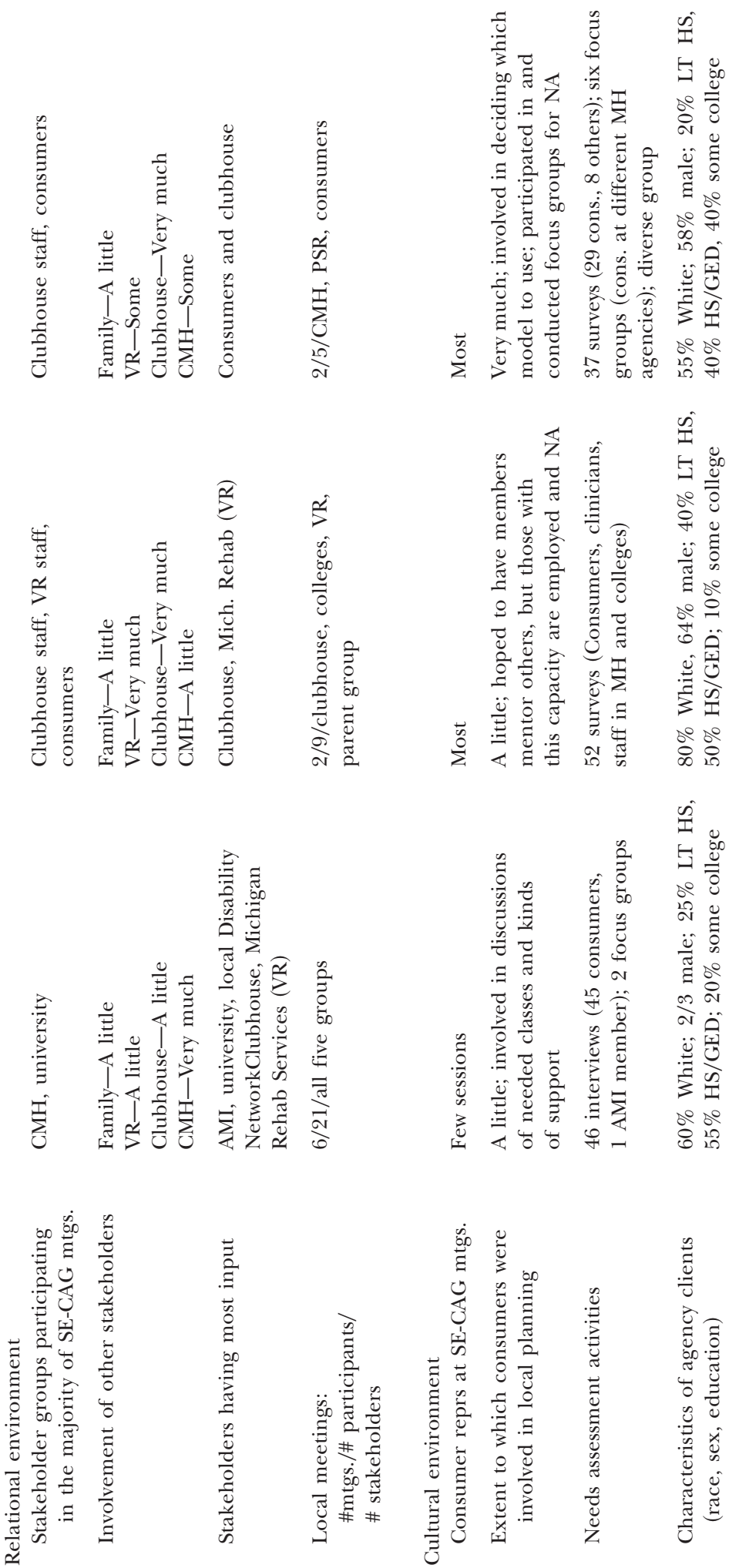


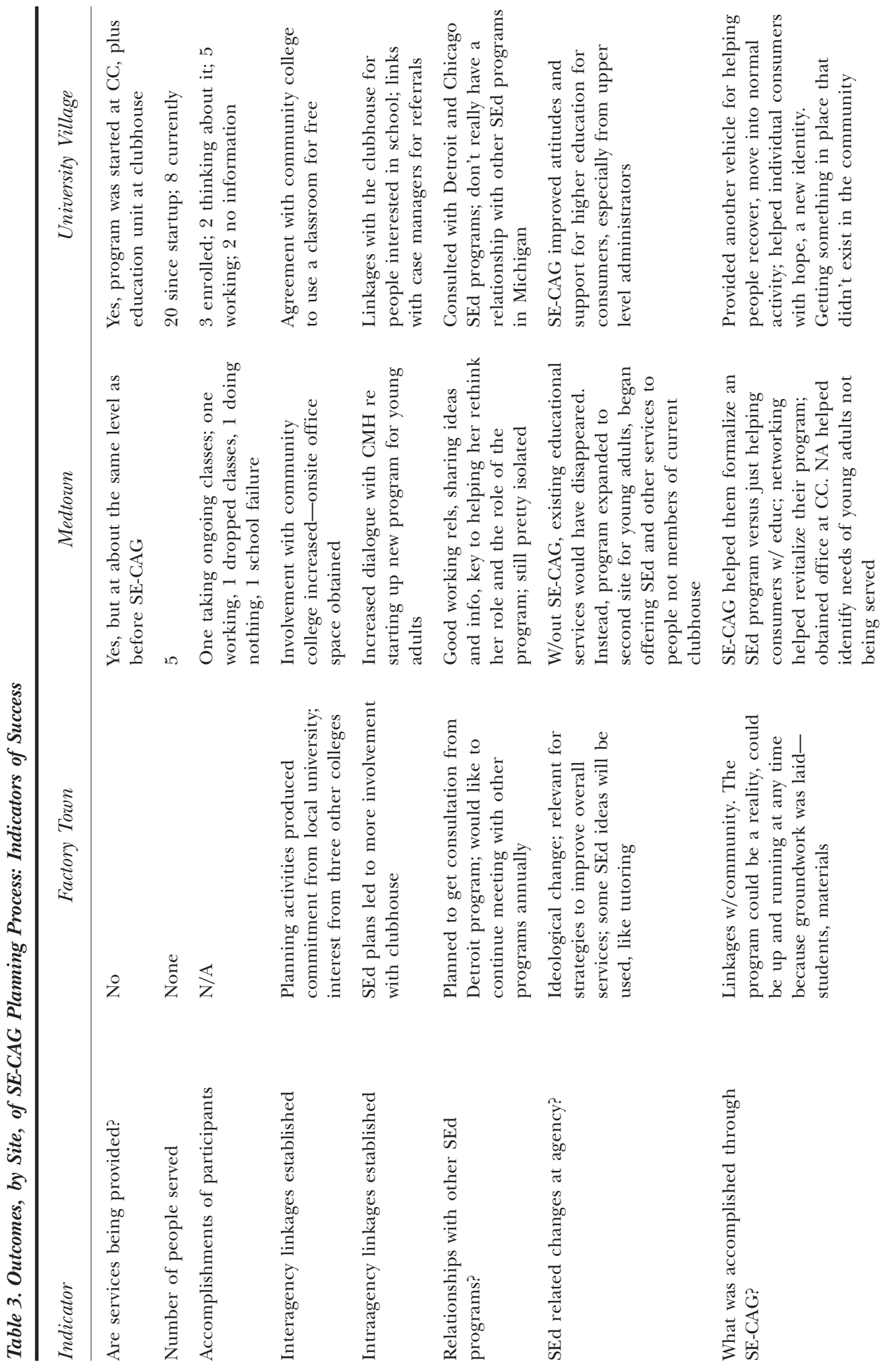



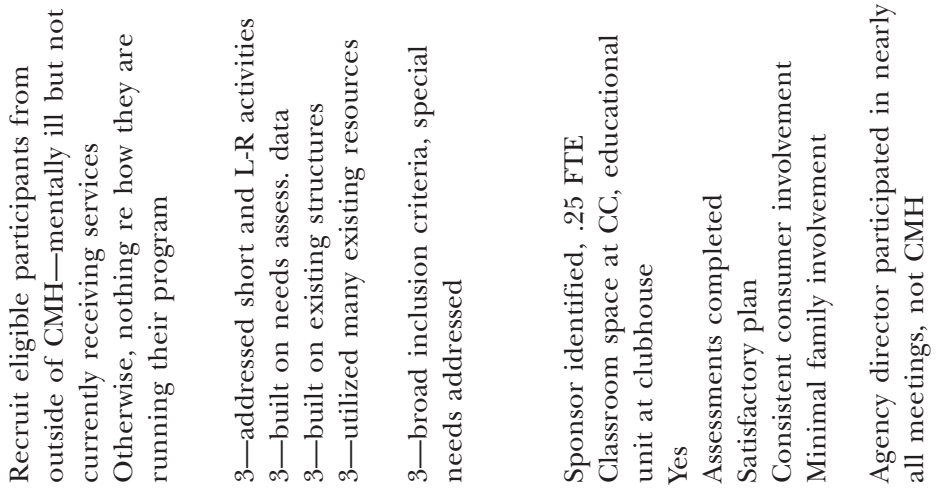

告产

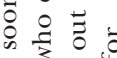

¿

¿

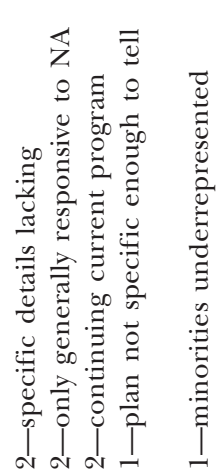

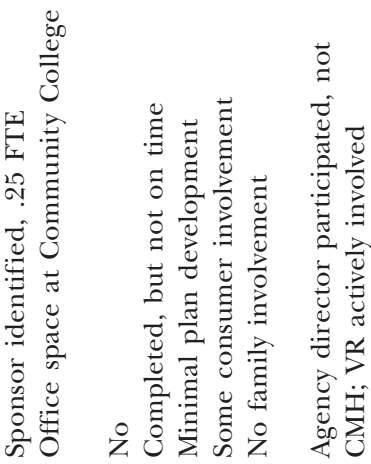

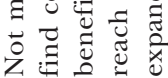

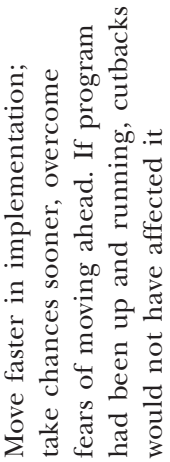

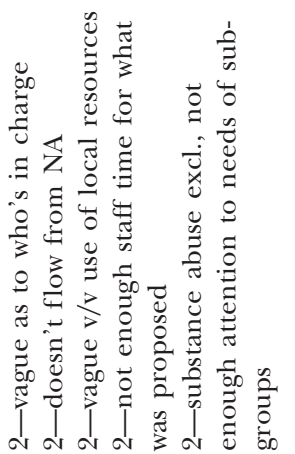

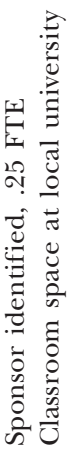

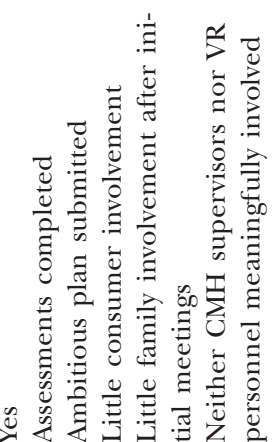

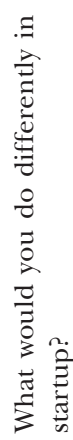

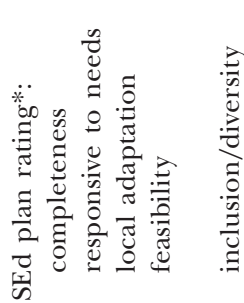

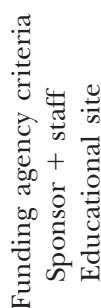

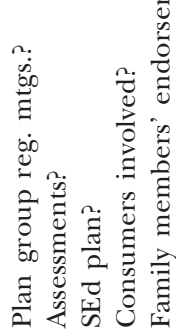

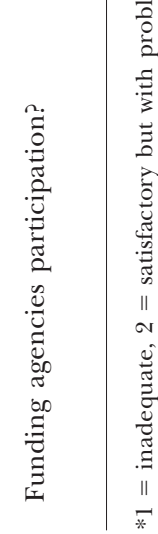


implemented. This contributed to wrangling and miscommunication among staff, supervisors leaving, reorganization, changes in reporting responsibilities, assignment of additional duties to staff involved, and eventually a hold on all new program initiatives. The individual staff assigned to the project followed the dictates of her supervisors and was not able to raise support for SEd. The participation of vocational rehabilitation (VR) staff, family members, consumers, and clubhouse members/staff dropped off shortly after the beginning of the project, so they could not be called upon as a constituency to help with SEd implementation. The result was that the Factory Town program ground to a halt before it even got underway.

In terms of outcomes, Factory Town has yet to implement any SEd programalthough, or perhaps because, it submitted the most ambitious implementation plan (50 students a year). The major obstacles were the fact that the proposed program had no upper level administrative backing, and the staff person in charge did not have sufficient experience, skill, status, or personal assertiveness to make it happen. This caused a delay in startup activities and in securing stakeholder involvement, which then led to the initiative coming under a new program freeze. As the staff initially assigned to develop SEd commented, "If the program had been running, cutbacks would not have affected it." It is interesting to note that this site did make substantial progress in establishing connections and obtaining commitments from local educational institutions. However, this did not help implementation, because the higher education sector was not seen as a major constituency by the CMH administration. Nevertheless, the SE-CAG project did raise some awareness of educational possibilities at a local clubhouse-a few of its members have gone back to school, receiving assistance from the college staff in the disability student services office. Clubhouse staff also report that they have initiated some education-related services, such as tutoring. There are hopes that when the site becomes more stabilized in staffing, organization, and funding, the groundwork will be in place for supported education to start.

\section{University Village}

Of the three sites selected for SE-CAG technical assistance, this one received the lowest initial scoring on the letter of intent and had the fewest number attending the initial orientation. However, in this site we saw the greatest eventual impact on the service delivery system. At the end of SE-CAG, University Village had the most participation from consumers and the most sustained and consistent interest from the clubhouse executive director. This individual was two levels down in the CMH hierarchy, but this clubhouse was situated better than the Medtown program because it was owned and operated by the CMH Board, not a contractual agency. University Village also experienced problems due to local circumstances; there was a reorganization, but the $\mathrm{CMH}$ director did not leave. Combined with budget cuts, this resulted in the first person assigned to SEd being transferred, a new SEd staff person being shifted to run this program and then being subsequently reassigned elsewhere. Nonetheless, it appears that the clubhouse Director's interest and commitment, plus that of staff and consumers, have been able to sustain the program. An educational unit has been put in place at the clubhouse, providing computers equipped with software enabling members to brush up their academic skills and acquire resource information for college and financial aid applications. Furthermore, utilizing the SE-CAG curriculum, a SEd class has been meeting twice a week for two semesters at the local 
community college, which donated space and provides access to free tutoring services. With these services in place, the Tri-County Scholars Program has successfully graduated three cohorts of students-a total of 20 individuals.

\section{OUTCOMES FOR OTHER SITES}

Of the sites that were not selected for SE-CAG technical assistance, Blue Collar Town had the best rating based on the advisory group's review of their letter of intent, and actually ranked higher than University Village and Factory Town in this first round. Although the group in Blue Collar Town was interested during the initial organizing meetings and had begun to work on their resource assessment, by their own analysis they did not have the cohesiveness and mutual focus to continue to plan for the development and implementation of an SEd program. As a result, they broke off the process after four meetings.

Transition City was ranked second to last on their letter of intent, despite the fact that they already had an individual assisting clubhouse members on return to college. This site's low rating and limited consumer interest could be due to the small population base, limited community resources, and low educational levels of community residents (usually eighth grade and below). Nevertheless, the SEd contact person came to many of the SE-CAG trainings. The site did develop an individual support system for clubhouse members interested in pursuing further education or training. At the end of the grant, the program had one student currently attending community college and eight students who were interested. Over time, consumer input and interest in the supported education efforts had increased substantially.

Two agencies from the Executive Village area initially submitted uncoordinated proposals and received the lowest scores for their letters of intent. Representatives did not attend many of the organized SE-CAG trainings, although they received consultation from both SE-CAG and MSEP. Eventually, they developed a full time Career Consultant who is working with local community colleges to get accommodations for students with psychiatric disabilities. She has submitted several grant proposals to establish a formal SEd program, and worked with two clubhouses in the area to acquire funding. This site is an economically advantaged area with residents who have achieved higher levels of education. Many consumers already have degrees and need help going back to school for specialized training or for an advanced degree to find work in a new area. The program now has about 20 students enrolled in school each semester, most of them in community colleges. With the help of SE-CAG, the site has an increased awareness of how to offer more effective supports and resources for students looking to (re)enter postsecondary education.

\section{DISCUSSION}

In discussing the SE-CAG project, we will first analyze its differential success and then speculate on the local circumstances which seem most predictive of outcomes across sites.

\section{Was the SE-CAG Planning Process Successful Overall?}

According to the criteria utilized by the federal funding agency, the answer is yes (see Table 3). At all three TA sites, there was a sponsoring agency for the initiative and 
commitment of staff resources, an educational site committed in-kind resources, the requested planning activities were carried out, consumers were at least minimally involved, and a plan was submitted. At two of these sites, family members were involved, a major funding agency was involved, and a planning committee met regularly. The larger question, though, is whether there was any programmatic impact from the planning activity. Clearly, there was an impact at two of the sites and perhaps some incremental changes at the third. The impact of the SE-CAG project is probably more demonstrable through a contrast of outcomes at the three TA sites versus the other sites that applied but were not selected for TA. In the latter group, only one site (with the most resources) produced concrete changes in SEd services available, on an individual basis, although there is still no identified SEd program. Another site expanded somewhat and kept going, just based on the training provided, while the third site stopped all activity.

\section{What Predicts Success?}

From analysis of differences across the three TA sites in this case study, the major factors related to success appear to be involvement of upper level staff, and the position of the staff assigned to SEd development in the administrative (power) hierarchy of the local CMH system, as well as active involvement by consumers. Reflecting back to Maton's (2000) dimensions, these factors seem most connected with the structural environment, vis-à-vis who has power and control. The findings are congruent with those of Kegler et al. (2000), who noted the significance of leadership and participation in effecting community change. Our findings also indicate the importance of building consensus among key stakeholders (MacFarlane, McNary, Dixon, Hornby, \& Cimett, 2001), in that in all the sites, at least several constituency groups had to come together for a successful effort.

Related to Rogers' (1995) framework, in our experience, the status and characteristics of the adopter and those of the change agent are significant. That is, in the most successful location, the staff assigned as change agent for SEd reported to a director who was involved in the planning process and proximal to those deciding on resources and adoption. In the least successful site, the change agent was structurally in a less influential position and had much less of the requisite skills and experience. Further, in this least successful site, the connection to the adopter (the CMH director position) was less proximal, and in fact, there was turnover in all the individuals occupying upper level administrative positions; one might say that there was no "adopter" available to make the change decision!

This case study is also congruent with Rogers' (1995) emphasis on the characteristics of the innovation; that is, the extent to which the proposed supported education initiative fits well with the values and needs of the agency. It is definitely more difficult to implement a new model if it varies significantly from current agency philosophy and practice (MacFarlane et al., 2001). In Medtown, there was a lack of fit with the educational aspirations of the agency's current clientele and with the community's more clinical versus rehabilitative and client-centered approach to service needs. In Factory Town, the clubhouse, where values are congruent with a SEd philosophy, did not have the lead for the initiative; rather the lead was given to the $\mathrm{CMH}$ vocational unit, which oversaw the clubhouse but took less of a client-centered and more of a traditional VR, medical model approach to services. Finally, University Village, the most successful site, had a history of and took pride in adopting new and innovative 
programs. We should also note that the educational level of the community appeared to play a role in successful implementation of SEd. Of the TA and the non-TA sites, the communities that were providing the most assistance in higher education pursuits at the end of the grant were those with higher average educational levels (according to census data, presented in Table 3).

The experience of this case study suggests some additional factors to consider for future predictions of success from community change and technology transfer/ innovation diffusion activities addressed to social problems. First, there is obviously a need to use a dynamic framework. In our readiness analysis, deciding which of the initial applicant communities would receive TA and resources, we assumed that letters of intent, describing stakeholder involvement and including signatures of stakeholder group representatives, would suffice. However, in retrospect, we would advise that this is only a starting point. Readiness and involvement must be continually monitored. Analyses must be dynamic-one needs to look at the state of the system now, but also where it is likely to be in the future (Backer, 2000). At our three TA sites, the initial level of involvement (number of people, number of stakeholder groups participating) was unrelated to eventual commitment and follow-through. In Factory Town, we saw many people from a large variety of stakeholder groups show up at the first orientation session. However, this reflected only an initial show of support or interest; the structure or skills were not there to pull a planning group together on an ongoing basis and to access their resources.

The dynamic nature of mental health systems also indicates the need to pay attention to timing. We suggest being wary of agencies involved in reorganization and leadership changes; they are not likely to be good candidates for program development or community change, especially if uncertainty about organizational finances is involved. MacFarlane et al. (2001) describe a similar situation in attempting to work with different state agencies in implementing family psychoeducational services. However, given the current unstable situation in funding, leadership, and policies for mental health services, it could be almost impossible to find agencies that are stable at the beginning of a program development effort and remain stable throughout!

Another aspect of our experience suggests the need for more attention to the structural environments of mental health systems in participating communities. As community organizers, we may optimistically assume that attempts to increase group empowerment will address power imbalances. However, the situation is likely to be more complex and difficult. In this case study, a significant flaw in our planning activities was that the choice of change agent was left to the discretion of those in power in the community; that is, what agency would take the lead and which staff would be assigned. Foster-Fishman, Salem, Allen, and Fahrbach (2001) note the importance of the skills and knowledge of change agents to community coalition success. In retrospect, the planning process should have provided more direction as to the most desirable leadership experience, skills, and position status of the individuals given responsibility for the SEd planning process. When an individual was appointed, the SE-CAG staff and the local stakeholders should have undertaken an assessment as to whether this individual had the necessary background skills, knowledge, and experience to work collaboratively with others and whether her position had the influential status needed to really act as a change agent. If not, several options could have been pursued. One would have been to request more involvement from agency leadership. Another would have been to attempt training the assigned staff in self-advocacy and 
community organizing methods. A final option would have been to provide additional support to the staff in terms of resource people to call for advice, other individuals to take on significant roles, etc. In our case, SE-CAG staff did offer to send letters to, meet with, or otherwise attempt to influence the CMH system's upper leadership. However, these were all declined by the staff, who probably saw such advocacy as being a threat in and of itself to her position, given her rather tenuous and below middlemanagement status.

As a note, the assignment by an agency of responsibility for program change activity to lower paid direct workers or the agency's embedded hierarchical structure, may be indicators of the need to select a different site or a different approach to change. That is, agencies that are not empowering staff are probably also not empowering clients; therefore, they may be ultimately resistant to getting clients more education. An alternative approach to change, rather than a community coalition, would be a top-down approach, convincing the $\mathrm{CMH}$ hierarchy somehow that the proposed change is really in their best interests and getting an endorsement of the effort from day 1.

Relevant to other issues in the literature, some discussion has been raised about the necessity of providing additional resources to fund program changes. Our experience suggests that resources are not everything, although funding probably does help. The TA initiative of SE-CAG did get services started-services carved out of current resources and so less likely to be eliminated when "special project" funding ends. Thus, new programs can be implemented without new funds to pay for them. However, if SE-CAG had not had at least some resources to help with local expenses, we may not have had any sites apply. Also, we would not have been able to "save" the Medtown program when existing funding was to be terminated due to the $\mathrm{CMH}$ Board's financial crisis.

The limitations of the present study need to be recognized. The project involved six communities in Michigan, not necessarily representative of the diversity in Michigan or elsewhere. We attempted to document, as concretely as possible, the values of the predictor and outcome variables. However, as research on communities, change processes and outcomes is still in its infancy, our measures may be subject to our biases and other limitations on judgement. Also, the time for follow-up was relatively short and outcomes over a much longer time frame could be quite different. Thus, we have tried to qualify our results and their implications. Readers are advised that this research has considerable limitations in terms of applications to other locations and/or to other community action initiatives.

\section{CONCLUSIONS}

This case study demonstrated that the SE-CAG planning framework, which reflected Maton's (2000) analysis of environmental characteristics significant to community change efforts, was a useful method for addressing local needs for a supported education program targeted to adults with psychiatric disabilities. The key factors that seemed most related to success in adopting a program, across three local sites, came from the structural environment dimension, reflecting involvement of and interest from agency leadership and consumers. Congruence with community values (in this case, $\%$ with higher education experience) also seemed relevant to success. In future analysis or planning for technology transfer in the social problems arena in local communities, we urge more attention to structural factors, such as the status and 
organizational location of the change agent, and to the dynamics of organizational change and the timing of change initiatives.

\section{REFERENGES}

Backer, T.E. (2000). The failure of success: Challenges of disseminating effective substance abuse prevention programs. Journal of Community Psychology, 28(3), 363-373.

Davis, H. (1978). Management of innovation and change in mental health services. Hospital and Community Psychiatry, 29, 649-658.

Fetterman, D.M. (2002). Empowerment evaluation: Building communities of practice and a culture of learning. American Journal of Community Psychology, 30(1), 89-103.

Fetterman, D.M., Kaftarian, S.J., \& Wandersman, A. (Eds.). (1996). Empowerment evaluation: Knowledge and tools for self-assessment \& accountability. Thousand Oaks, CA: Sage.

Foster-Fishman, P.G., Salem, D.A., Allen, N.A., \& Fahrbach, K. (2001). Facilitating interorganizational collaboration: The contributions of interorganizational alliances. American Journal of Community Psychology, 29(6), 875-905.

Gutierrez, L., GlenMaye, L., \& DeLois, K. (1995). The organizational context of empowerment practice: Implications for social work administration. Social Work, 40(2), 249-258.

Herie, M., \& Martin, G.W. (2002). Knowledge diffusion in social work: A new approach to bridging the gap. Social Work, 47(1), 85-95.

Kegler, M.C., Twiss, J.M., \& Look, V. (2000). Assessing community change at multiple levels: The genesis of an evaluation framework for the California Healthy Cities Project. Health Education and Behavior, 27(6), 760-799.

Maton, K.I. (2000). Making a difference: The social ecology of social transformation. American Journal of Community Psychology, 28(1), 25-57.

MacFarlane, W.R., McNary, S., Dixon, L., Hornby, H., \& Cimett, E. (2001). Psychiatric Services, 52(7), 935-942.

Minkler, M. (1997). Community organizing and community building for health. New Brunswick, NJ: Rutgers University Press.

Mizrahi, T., \& Rosenthal, B.B. (2001). Complexities of coalition building: Leaders' successes, strategies, struggles and solutions. Social Work, 46(1), 63-78.

Mowbray, C.T., Bellamy, C., Megivern, D., \& Szilvagyi, S. (2001). Raising our sites: Dissemination of supported education. Journal of Behavioral Health Services and Research, 28(4), 484-491.

Moxley, D.P., Mowbray, C.T., \& Brown, K.S. (1993). Supported education. In P.W. Flexler, \& P. Solomon (Eds.), Psychiatric rehabilitation in practice. Boston: Andover Medical Publishers.

Rogers, E.M. (1995) Diffusion of innovations (4th ed.). New York: The Free Press.

U.S. Census Bureau. State and County QuickFacts, Michigan. 2000 Census of Population and Housing and 1990 Census of Population and Housing. Retrieved June 23, 2002 at http:// quickfacts.census.gov/qfd/states/26000.html.

Wondolleck, J.M., \& Yaffee, S.L. (2000). Making collaboration work: Lessons from innovation in natural resource management. Washington, DC: Island Press.

Wolff, T.M. (2001). A practitioner's guide to successful coalitions. American Journal of Community Psychology, 29(2), 173-191. 